\title{
The ground-based MW radiometer OZORAM on Spitsbergen - description and status of stratospheric and mesospheric $\mathrm{O}_{3}$-measurements
}

\author{
M. Palm, C. G. Hoffmann, S. H. W. Golchert, and J. Notholt \\ IUP, Universität Bremen, Bremen, Germany \\ Received: 5 March 2010 - Published in Atmos. Meas. Tech. Discuss.: 22 April 2010 \\ Revised: 2 November 2010 - Accepted: 4 November 2010 - Published: 9 November 2010
}

\begin{abstract}
This manuscript introduces the OZORAM ground-based millimeter wave radiometer. The instrument is deployed to the high Arctic $\left(79^{\circ} \mathrm{N}, 12^{\circ} \mathrm{E}\right)$ for measurements of $\mathrm{O}_{3}$ in the upper stratosphere and lower mesosphere.

The publication describes the status of OZORAM in the end of 2010. OZORAM is able to provide profile information between 30 and $70 \mathrm{~km}$ altitude in time intervals of $1 \mathrm{~h}$.

To establish applications of the data and to investigate instrumental biases, the results from September 2008 till summer 2010 are compared to $\mathrm{O}_{3}$ profiles derived from measurements of two instruments onboard polar orbiting satellites, MLS onboard EOS-AURA and SABER onboard TIMED. The agreement is within $10 \%$ in the middle and upper stratosphere and 30\% in the lower mesosphere. The deviation shows systematic and oscillating features which are, however, constant during the period of comparison.

The data set is therefore suitable for studies of mesospheric and stratospheric response to changes in dynamics or due to solar influences on climate.
\end{abstract}

\section{Introduction}

$\mathrm{O}_{3}$ is an atmospheric component of major interest. The stratosphere, synonymous with the $\mathrm{O}_{3}$ layer, filters most of the UV radiation and thus allows life on Earth outside water. While the $\mathrm{O}_{3}$ layer, and its depletion due to anthropogenically released chemicals, was a major research topic throughout the 1990s, the focus of $\mathrm{O}_{3}$ research has recently shifted upwards towards the upper stratosphere and the mesosphere.

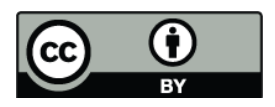

Correspondence to: M. Palm (mathias@iup.physik.uni-bremen.de)
The mesosphere/lower thermosphere (MLT-region) forms the interface between atmosphere and outer space. Radiation and particles from the sun and outer space enter the MLT-region and release energy there or even penetrate into the upper stratosphere. They trigger a whole class of chemical reactions, the ion chemistry, leading to the formation of hydrogen and nitrogen radicals which catalytically destroy $\mathrm{O}_{3}$. While hydrogen radicals are most effective in the lower mesosphere (Lary, 1997) and decay on a timescale of hours to days, nitrogen radicals travel deep into the stratosphere by large scale descent of mesospheric and thermospheric air during polar winter (Randall et al., 2005). Nitrogen radicals become effective in $\mathrm{O}_{3}$ destruction in the upper stratosphere (Lary, 1997). Hence, solar activity can exert strong influence on stratospheric chemistry and on the $\mathrm{O}_{3}$-layer.

$\mathrm{O}_{3}$ is involved in much of the atmospheric chemistry, and its atmospheric content is sensitive to changes in irradiation. The information about its distribution in the atmosphere is easily accessible due to its numerous molecular transitions, causing strong absorption throughout the IR and millimeter wave spectrum. Measurements in the millimeter wave region using passive ground-based measurements are particularly suited to mesospheric studies because profile information can be accessed well into the lower mesosphere.

Passive millimeter wave radiometry has been used to study properties of the atmosphere as early as in the 70ies (Waters, 1973; Waters et al., 1976). Rotational emissions of $\mathrm{O}_{3}$ have been measured by Penfield et al. (1976), but only in the upper stratosphere and mesosphere due to limited spectral bandwith. After the discovery of the $\mathrm{O}_{3}$-hole (Farman et al., 1985) the instruments where successively extended to measure in the lower stratosphere (Connor et al., 1994; Sinnhuber et al., 1998, e.g.). The need for continuous monitoring of the stratospheric response to anthropogenic trace gas releases, performed by a well defined set

Published by Copernicus Publications on behalf of the European Geosciences Union. 
of instruments, led to the foundation of the Network for the Detection of Stratospheric Change (NDSC) (now Network for the Detection of Atmospheric Composition Change NDACC $^{1}$ ) in 1991. The AWIPEV station, including the OZORAM instrument, is part of this network. There have been a number of comparisons in the past, showing that millimeter wave radiometers are a reliable tool to measure stratospheric and mesospheric $\mathrm{O}_{3}$ (Connor et al., 1994; Tsou et al., 1995; Hocke et al., 2007; Boyd et al., 2007).

Passive millimeter wave measurements of atmospheric trace gases offer a range of unique features. They are independent of solar or lunar irradiation and largely insensitive to weather conditions. The measurements have a good time resolution of $1 \mathrm{~h}$ and capture a narrow and well defined trace through the atmosphere.

This publication describes instrumental aspects of the Ozone Radiometer for Atmospheric Measurements (OZORAM), a ground-based microwave radiometer located on the Spitsbergen archipelago, and introduces the data set extracted from its measurements since 2008. In order to retrieve the $\mathrm{O}_{3}$-profile from the measurements, two spectroscopic catalogs have been used, the 2004 HITRAN catalog (Rothman et al., 2005) and the 2009 JPL catalog (Pickett et al., 2010), appended with spectroscopic parameters by the ARTS package (see Sect. 2.4 for further details). The data sets are called OZORAM-HIT and OZORAM-JPL, respectively.

The instrument has been modified to enable measurements of mesospheric $\mathrm{O}_{3}$. Section 2 describes the instrument and the retrieval methods that extract information from the measurements. A retrieval assessment and an error characterization of the measurements conclude this section.

In Sect. 3, the data available from autumn 2008 until summer 2010 are compared to two space borne instruments that measure the polar winter atmosphere, i.e. EOS MLS onboard the Aura satellite (Schoeberl et al., 2006) and SABER onboard the TIMED satellite (Russell III et al., 1994).

\section{The OZORAM instrument}

\subsection{General}

The OZORAM instrument is located at the AWIPEV research base in Ny-Ålesund $\left(79.9^{\circ} \mathrm{N}, 11.9^{\circ} \mathrm{E}\right)$ on the Spitsbergen archipelago. It is jointly operated by the Alfred Wegener Institute (AWI) and the Universität Bremen. It has been committed to operation in 1994 (Sinnhuber et al., 1998) and has been modified for measurements of mesospheric emissions in 2006-2008 (for a history of the instrument see Table 1).

\footnotetext{
$1_{\text {www.ndacc.org }}$
}

Table 1. Summary of OZORAM characteristics. The altitude range and altitude resolution depend on integration time. The figures given here correspond to a measurement interval of $1 \mathrm{~h}$. For the difference in altitude range refer to Sect. 2.2. Data recorded until 2004 have been used in past publications (Sinnhuber et al., 1998; Klein et al., 2000, 2002) and are listed here for completeness.

\begin{tabular}{lllll}
\hline & pre 2004 & $2006-2007$ & $2007-2008$ & from 2008 \\
\hline Backend & AOS & AOS + CTS & FFTS & FFTS \\
Sys. NT & $3500 \mathrm{~K}$ & $1100 \mathrm{~K}$ & $1100 \mathrm{~K}$ & $1100 \mathrm{~K}$ \\
Band width & $1.5 \mathrm{GHz}$ & $1 \mathrm{GHz}$ & $0.5 \mathrm{GHz}$ & $0.8 \mathrm{GHz}$ \\
Resolution & $1.5 \mathrm{MHz}$ & $1.5 \mathrm{MHz}+10 \mathrm{kHz}$ & $60 \mathrm{kHz}$ & $60 \mathrm{kHz}$ \\
Alt. range & $15-40 \mathrm{~km}$ & $15-60 \mathrm{~km}$ & $30-60 \mathrm{~km}$ & $25-70 \mathrm{~km}$ \\
\hline
\end{tabular}

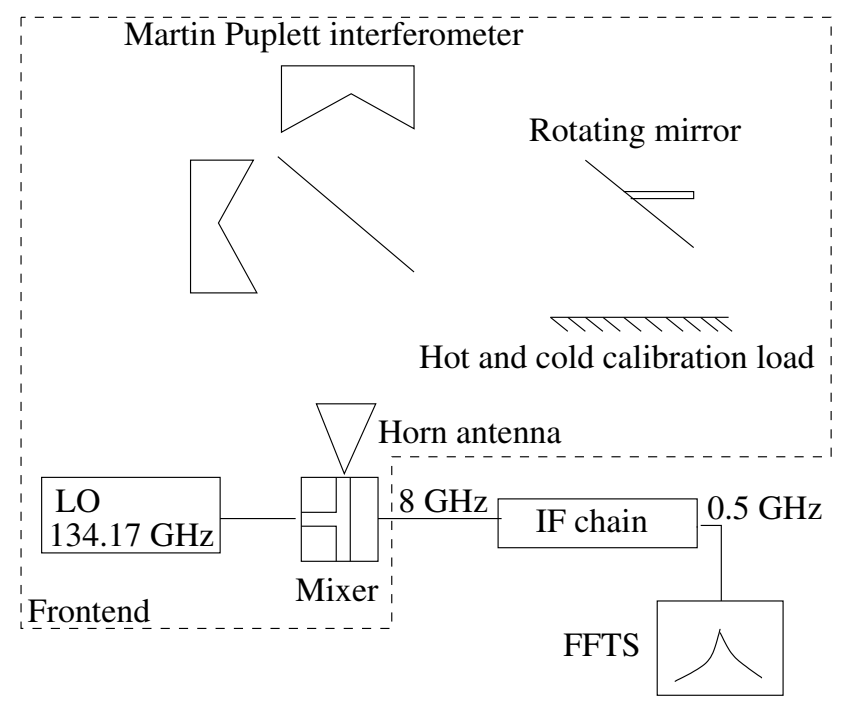

Fig. 1. Overview sketch of the OZORAM. Technical details are described in Klein (1993) and have been omitted for clarity. The dashed line encloses the front end with the quasi optical system and the first mixing stage.

\subsection{The ground-based millimeter wave radiometer OZORAM}

OZORAM is a heterodyne single side-band receiver tuned to the $142.176 \mathrm{GHz}$ emission line $\left(10_{1,9} \rightarrow 10_{0,10}\right)$ of $\mathrm{O}_{3}$. The bandwidth is $800 \mathrm{MHz}$ and the frequency resolution is approx. $60 \mathrm{kHz}$. Its main building blocks are (see Fig. 1):

Front end. This consists of a quasi optical system and Schottky mixer followed by a low noise HEMT amplifier. The quasioptical system selects the radiation source from hot black body, cold black body and the atmosphere, respectively. A Martin-Puplettinterferometer is used to suppress the mirror side band at $126 \mathrm{GHz}$ with at least $20 \mathrm{~dB}$ attenuation. The signal is down-converted to $8 \mathrm{GHz}$ intermediate frequency.

IF chain. This is responsible for filtering, amplification, and further down conversion of the $8 \mathrm{GHz}$-signal to fit the spectrometer input (DC $-1 \mathrm{GHz})$. 
Spectrometer. The Fast-Fourier-transform (FFT) spectrometer Agilent AC240 (Benz et al., 2005) comprises fast AD converters and an FPGA (field programmable array)-implemented Fourier transformer. It delivers a bandwidth of $1 \mathrm{GHz}$ and a resolution of approx. $60 \mathrm{kHz}$. The Fourier transformation is calculated in real time.

OZORAM is operated in total power mode, alternately taking measurements from a hot black body, $V_{\mathrm{H}}\left(T_{\mathrm{H}}=293 \mathrm{~K}\right)$, the atmosphere, $V_{\mathrm{A}}$, and a cold black body, $V_{\mathrm{C}}\left(T_{\mathrm{C}}=77 \mathrm{~K}\right)$. The black bodies have an emissivity of better than $99 \%$ in the millimeter wave frequency region. The black body measurements, $V_{\mathrm{H}}$ and $V_{\mathrm{C}}$, are recorded for calibration purposes. The calibrated spectrum, $y$, can be calculated using the Planck formula, $B_{T}$, for black body radiation at temperature $T$ :

$y=\frac{B_{T_{\mathrm{H}}}-B_{T_{\mathrm{C}}}}{V_{\mathrm{H}}-V_{\mathrm{C}}}\left(V_{\mathrm{A}}-V_{\mathrm{C}}\right)+B_{T_{\mathrm{C}}}$

The receiver can be characterized via the receiver-noisetemperature ${ }^{2}, T_{\mathrm{REC}}$, which quantifies the noise contribution of the instrument to the measurement (Janssen, 1993). The standard deviation of the noise on the measurement, $\sigma_{y}$, is proportional to the system temperature $T_{\mathrm{SYS}}=T_{\mathrm{REC}}+T_{\mathrm{SIG}}$ with $T_{\text {SIG }}$ the temperature of the signal. The standard deviation of a measurement can be estimated via the radiometric formula:

$\sigma_{y}=\frac{T_{\mathrm{SYS}}}{\sqrt{v t}}$

with the bandwidth, $v$, and the integration time, $t$.

See Fig. 3 for an example of a calibrated spectrum recorded in winter 2009 and Fig. 4 for the profile (in black) retrieved from it (for the retrieval see Sect. 2.5). The night time profile exhibits an enhancement in mesospheric $\mathrm{O}_{3}$ as is expected in the absence of solar illumination. A day time profile is plotted (in blue) for comparison, retrieved from a spectrum taken $12 \mathrm{~h}$ later. The shaded areas are standard deviations of the retrieved profiles as discussed in Sect. 2.6.

This publication accounts for the status of the instrument from 2008 to 2010. During summers 2006, 2007 and 2008, several modifications and optimizations were carried out in order to extend observations into the mesosphere (Sect. 2.2). Between 2006 and 2008 the data have different performance specifications, which are reported separately in Table 1 . They can only be used with care. Since autumn 2008 the OZORAM is fully operational in the mesosphere mode.

\section{Modifications between 2006-2008}

During the winter 2006/2007 an acousto-opticalspectrometer (AOS) covered the broad band portion of the spectrum, in parallel with a chirp-transformspectrometer (CTS) resolving the line center. This combination has been used because the resolution of the AOS

\footnotetext{
2 The quantities $T$, which is a power and in millimeterwave radiometry given in the unit $\mathrm{K}$ and $V$ which is the readout of the spectrometer, usually a voltage or a count number. $T$ and $V$ are related by a scalar calibration factor $c$, which depends on the instrument.
}

was not sufficient to resolve the mesospheric information at the line center. Due to permanent failure of the AOS, this combination was replaced later by the FFT spectrometer.

From 2006 through 2008, the spectra were recorded within time intervals of $20 \mathrm{~min}$ alternating with a front end tuned to the $22.2 \mathrm{GHz}$ emission line of a water vapor transition. Prior to 2008 , only about one third of the available time was used for $\mathrm{O}_{3}$ measurements, which significantly reduces the SNR. This explains the difference in the maximum upper altitude reported in Table 1, 3rd column. Since autumn 2008, the system is only used for $\mathrm{O}_{3}$ measurements. The spectra are recorded in portions of about 10 min measuring time. In order to achieve a sufficient SNR, the calibrated spectra are further integrated, so that one spectrum is available per hour.

\subsection{Measurement geometry}

The direction of the viewing path, given by the azimuth angle, $113^{\circ}$, and the elevation angle, $20^{\circ}$, has to be taken into account when comparing with models and/or other instruments and also for interpreting short time variations. See Fig. 2 for a plot of the measurement location and the viewing path.

\subsection{The radiative transfer}

Radiative transfer is encoded in the forward model ARTS ${ }^{3}$ (Bühler et al., 2005) and is only cursorily described in this publication. For a detailed account of the radiative transfer theory the reader is referred to any textbook dealing with the matter (e.g. Janssen, 1993). The formulae for the radiative transfer are documented in the ARTS user guide (part of the ARTS package and also available for download). Melsheimer et al. (2005) investigated the ARTS radiative transfer and compared it to other models.

Formally, the forward model denotes a function, $\boldsymbol{y}=$ $F(\boldsymbol{x}, \boldsymbol{b})$, which yields a spectrum, $\boldsymbol{y}$, for a given atmospheric state, $\boldsymbol{x}$, and a set of auxiliary parameters, $\boldsymbol{b}$. The atmospheric state comprises one or several trace gas profiles, usually given on a pressure grid. The auxiliary parameters include an atmospheric temperature profile, spectroscopic data of the observed transitions, and parameters of the instrument.

\subsubsection{Absorption and emission in a fixed layer}

The details of calculating the absorption coefficient $\alpha(v)$ are omitted here as it has been investigated in great detail by several authors (e.g. Janssen, 1993).

Nevertheless, notable are a few facts: The absorption coefficient consists of two parts: the strength of the absorption due to the absorption by the molecules and the shape of the absorption strengths versus energy (= frequency) due to the finite lifetime of the excited states.

\footnotetext{
${ }^{3}$ For the retrievals presented here, ARTS version 1.0.216 is used, which is available for download at http://www.sat.ltu.se/.
} 
Table 2. Spectroscopic parameters for the retrieval of the data sets presented in this work.

\begin{tabular}{|c|c|c|c|c|}
\hline Quantity & & Unit & OZORAM-HIT & OZORAM-JPL \\
\hline Line center & $v_{0}$ & $\mathrm{GHz}$ & 142.17657 & 142.17504 \\
\hline Line intensity & $I_{0}$ & $\mathrm{~m}^{2} \mathrm{~Hz}$ & $7.0834 \times 10^{-17}$ & $7.0746 \times 10^{-17}$ \\
\hline Pressure broadening & $\gamma_{\mathrm{AIR}}\left(T_{0}\right)$ & $\mathrm{Hz} / \mathrm{Pa}$ & 24498 & 25000 \\
\hline $\begin{array}{l}\text { Self broadening } \\
\text { Temperature dependance }\end{array}$ & $\gamma_{\mathrm{SELF}}\left(T_{0}\right)$ & $\mathrm{Hz} / \mathrm{Pa}$ & 31184 & 25000 \\
\hline $\begin{array}{l}\text { of } \gamma_{\mathrm{AIR}}\left(T_{0}\right) \\
\text { Temperature dependance }\end{array}$ & $n_{\mathrm{AIR}}$ & & 0.71 & 0.75 \\
\hline of $\gamma_{\mathrm{SELF}}\left(T_{0}\right)$ & $n_{\text {SELF }}$ & & 0.71 & 0.75 \\
\hline
\end{tabular}
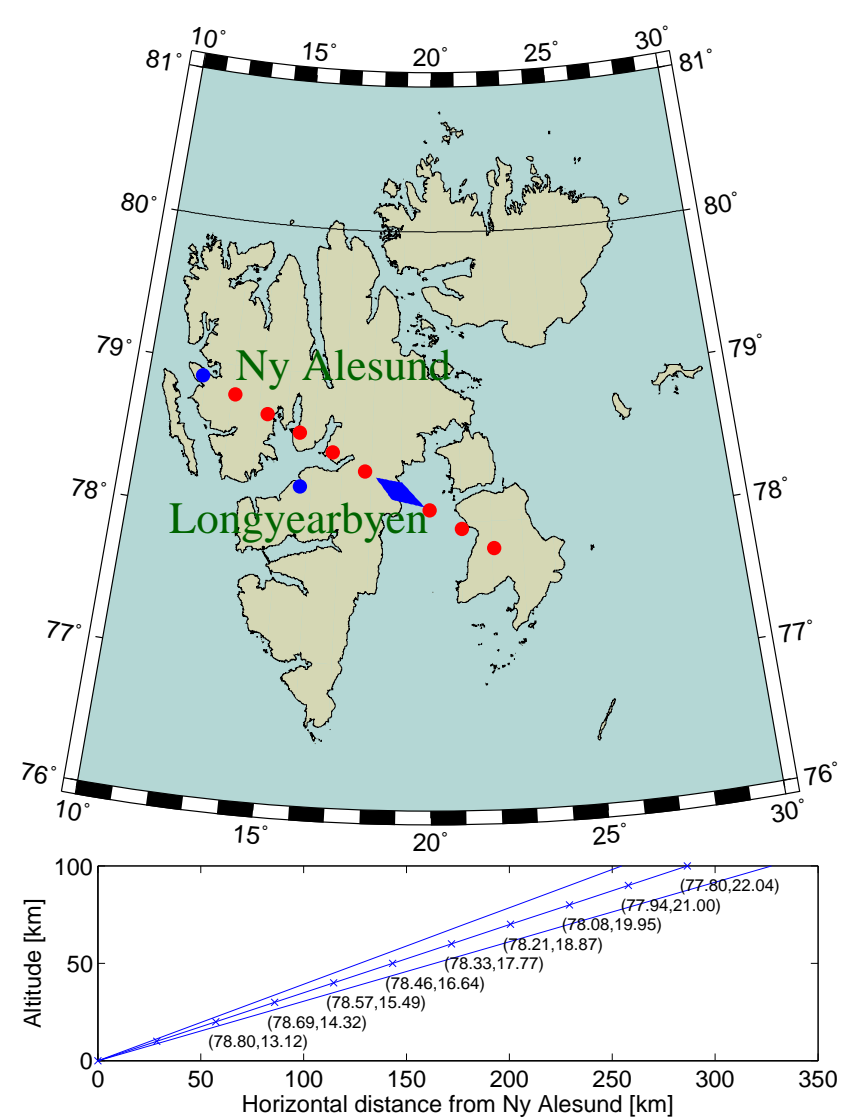

Fig. 2. OZORAM measurement geometry. The upper panel shows the ground track of the viewing path. The dots denote the viewing path in $10 \mathrm{~km}$ steps. The diamond is the measured region of the at $60 \mathrm{~km}$ altitude. The lower panel denotes the viewing path in the plane given by azimuth and zenith directions.

In spectral catalogues, the absorption coefficient is parametrized by a number of values: $\nu_{0}$ - the frequency, $I_{0}$ - the intensity, $\gamma_{\text {AIR }}$ - the broadening of the line due to collisions with air molecules except the one under consideration, $\gamma_{\text {SELF }}-$ the broadening of the line due to collision with molecules of the same kind. The latter three values are defined at a specified temperature. The dependency of $\gamma_{\text {AIR }}$ and $\gamma_{\text {SELF }}$ on the temperature is parametrized by two parameters, denoted by $n_{\text {AIR }}$ and $n_{\text {SELF }}$, respectively. The spectrometric parameters used for the retrieval of the data sets are summarized in Table 2.

The absorptivity at a well defined place in the atmosphere furthermore depends on the chemical composition, pressure and temperature.

\subsubsection{The modeling of the spectrum}

In neglect of scattering, which is justified for millimeter wave radiation in absence of precipitation, the locally generated radiation at frequency $v, S(v)$, and absorptivity $\alpha(v)$ of the same volume are connected via Kirchhoff's law of thermal radiation (Janssen, 1993):

$\frac{S(v)}{\alpha(v)}=B(T, v)$

with $B(T, v)$ the Planck function for the temperature $T$. The spectrum itself, $y$, is the integral of all emission and absorption along the line of sight from the sensor location, $s_{0}$, to the top of the atmosphere, $s_{\infty}$. In the following the frequency dependence of $\alpha$ and $y$ is disregarded for clarity. $\alpha(s)$ is the absorptivity at position $s$ of the line of sight. Hence $\alpha(s)$ incorporates the dependency of the absorptivity on the species under consideration, given by the abundance profile $\boldsymbol{x}$ and the atmospheric pressure and temperature profiles.

$$
\begin{aligned}
& y=F(\boldsymbol{x}, \boldsymbol{b})=y_{\infty} \exp \left(-\tau\left(s_{0}, s_{\infty}\right)\right) \\
& +\int_{s_{0}}^{s_{\infty}} \underbrace{\alpha(s) B(T(s))}_{\text {emission }} \overbrace{\exp \left(-\tau\left(s_{0}, s\right)\right)}^{\text {absorption }} d s .
\end{aligned}
$$

The spectrum measured at $s_{\infty}$, here the Planck radiation of space, is denoted by $y_{\infty} \cdot \tau\left(s_{1}, s_{2}\right)=\int_{s_{1}}^{s_{2}} \alpha(s) d s$ is the opacity between $s_{1}$ and $s_{2}$ along the line of sight.

\subsubsection{Summary of the radiative transfer}

The following elements of radiative transfer are stated for their importance in the discussion to follow. For instruments with a zenith looking measurement geometry the following statements hold: 


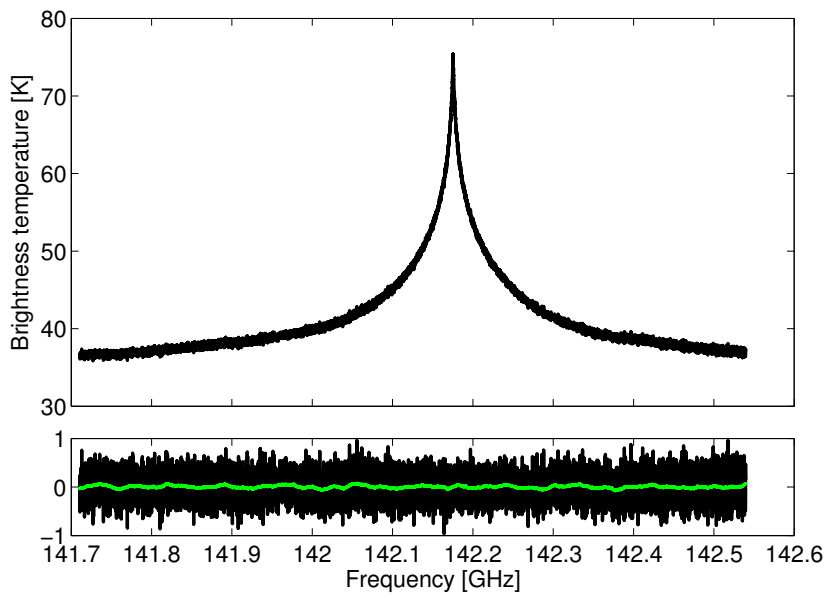

Fig. 3. A spectrum measured on the 25 February 2009, mid night (UTC). The lower figure shows the residuum after profile retrieval (See Fig. 4). A running mean has been applied to the residuum.

1. For the $142 \mathrm{GHz} \mathrm{O}_{3}$ emission, the pressure determines the line-width up to an altitude of about $55 \mathrm{~km}$. Above $65 \mathrm{~km}$ it is governed by temperature. In the range in between, it is determined by a mixture of temperature and pressure effects commonly represented in the Voigt line shape (Janssen, 1993).

2. Roughly, the line center of the absorption coefficient of $\mathrm{O}_{3}$ is proportional to the volume-mixing-ratio (VMR) (this is strictly true in the pressure broadening regime; Janssen, 1993, Sect. 2.4.2).

3. The radiation created in a given altitude is attenuated by the absorption in lower altitudes. If there is an error in the absorptivity calculation at a certain altitude it will not only affect the result for this altitude but also the results for all altitudes above.

\subsection{The retrieval}

\subsubsection{Retrieval setup}

The spectra are analyzed using the optimal estimation method (Rodgers, 2000). Optimal estimation is a statistically founded method in which the result, $\hat{\boldsymbol{x}}$, given the measurement, $\boldsymbol{y}$, is the largest value of the conditional probability density

$$
\begin{aligned}
p(\hat{\boldsymbol{x}} \mid \boldsymbol{y}) \sim & \exp \left(-(F(\hat{\boldsymbol{x}})-\boldsymbol{y}) \mathbf{S}_{\epsilon}^{-1}(F(\hat{\boldsymbol{x}})-\boldsymbol{y})^{T}\right) \\
& \times \underbrace{\exp \left(-\left(\boldsymbol{x}_{\mathrm{A}}-\hat{\boldsymbol{x}}\right) \mathbf{S}_{\mathrm{A}}^{-1}\left(\boldsymbol{x}_{\mathrm{A}}-\hat{\boldsymbol{x}}\right)^{T}\right)}_{\text {a priori }}
\end{aligned}
$$

The a priori, Eq. (6), is necessary as a regularization of this often under-constrained problem and restricts the results using a Gaussian with mean $\boldsymbol{x}_{\mathrm{A}}$, the a priori profile, and the

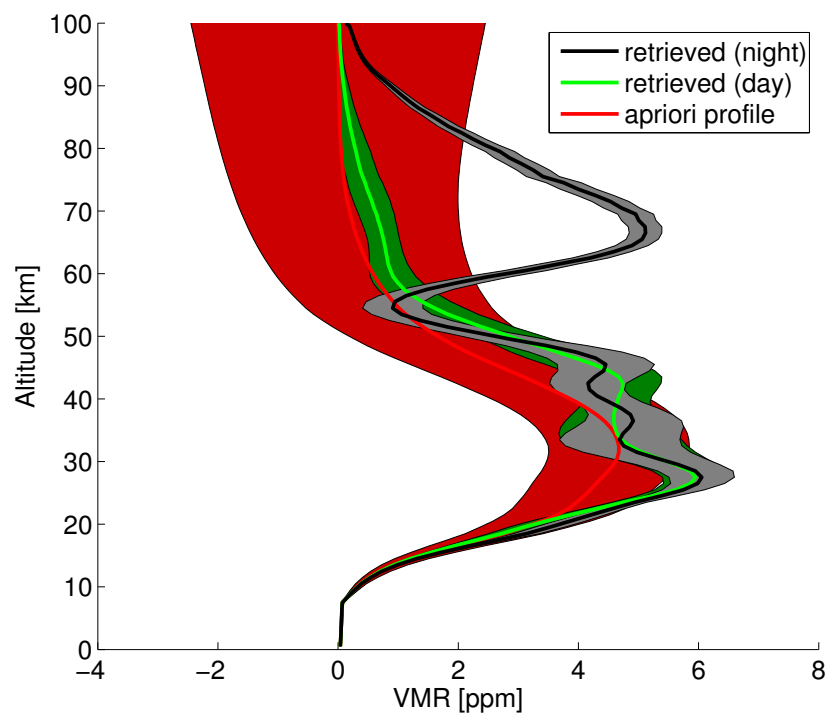

Fig. 4. $\mathrm{O}_{3}$ profiles retrieved during night (black) and day (green) and the a priori profile (red). The spectrum shown in Fig. 3 corresponds to the night time spectrum. The shaded regions (green, black) are the uncertainties caused by the total error as derived in Sect. 2.6. The red shaded region is the a priori standard deviation used in the retrieval.

a priori covariance matrix, $\mathbf{S}_{\mathrm{A}}$. The noise covariance, $\mathbf{S}_{\epsilon}$, describes the Gaussian model of the statistical noise, $\epsilon$, on the measurement (with mean $\bar{\epsilon}=0$ ).

The noise covariance matrix, $\mathbf{S}_{\epsilon}$, is calculated from the system noise temperature, Eq. (2) with an error propagation calculation following Eq. (1). The a priori profile, $\boldsymbol{x}_{\mathrm{A}}$, is a mean daytime $\mathrm{O}_{3}$ profile (adapted from the FASCOD subarctic winter climatology) that has been smoothed in order to reflect the low altitude resolution of the data. The $\mathbf{S}_{\mathrm{A}}$ matrix has only diagonal entries, i.e. inter-layer correlations were not taken into account. The standard deviation is defined to be $20 \%$ ( 0.1 to $0.9 \mathrm{ppmv}$ ) of the $\mathrm{O}_{3}$ a priori VMR up to an altitude of $40 \mathrm{~km}$ and rising to $3 \mathrm{ppmv}$ at $100 \mathrm{~km}$ altitude (see Fig. 4, for the a priori profile and the square root of the a priori variance in red). The analysis is performed using a pressure grid corresponding to fixed altitude levels from $0.5 \mathrm{~km}$ to $100.5 \mathrm{~km}$ with a spacing of $1 \mathrm{~km}$. The atmospheric temperature and geopotential height profiles are taken from ECMWF Operational Analysis data. The ECMWF data are availabel every $6 \mathrm{~h}$ starting from $0 \mathrm{~h}$ on a $1.5 \times 1.5^{\circ}$ grid and 91 altitude layers. The data have been interpolated to the geometrical location, exact time and altitude grid. The ECMWF data are extended to $100 \mathrm{~km}$ altitude using a default temperature profile (FASCOD, subarctic winter scenario)and the hydrostatic equation.

Using the Jacobian of the forward model $F(\boldsymbol{x}, \boldsymbol{b})$ with respect to $\boldsymbol{x}$, also called the weighting function matrix $\mathbf{K}, \hat{\boldsymbol{x}}$ is found by Rodgers (2000):

$\hat{\boldsymbol{x}}=\boldsymbol{x}_{\mathbf{A}}+\underbrace{\left(\mathbf{S}_{\mathrm{A}}^{-1}+\mathbf{K} \mathbf{S}_{\epsilon} \mathbf{K}^{T}\right)^{-1} \mathbf{K}^{T} \mathbf{S}_{\epsilon_{\mathbf{D}}}}\left(\boldsymbol{y}-\mathbf{K} \boldsymbol{x}_{\mathrm{A}}\right)$. 

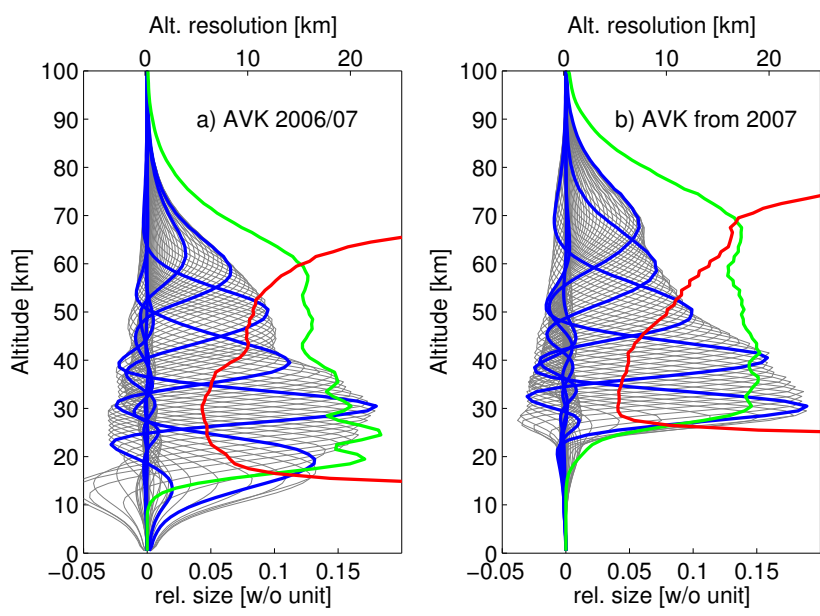

Fig. 5. Averaging kernels for the periods 2006/2007 (left panel) and 2008 onwards (right panel). Thick blue lines indicate averaging kernels (AVK) for the values at 30, 40, 50, 60, and $70 \mathrm{~km}$ altitude. Green solid lines denote sums of the AVKs, divided by 10 . Solid red lines correspond to altitude resolution, given as FWHM of the Gaussian approximation to the AVKs, at the respective altitudes (axis at figure tops). The differences in the AVKs reflect the hardware changes as described in Sect. 2.2.

D is called the contribution function matrix and can be regarded as the inverse of the weighting function matrix $\mathbf{K}$.

The setup contains the retrieval of three main parameters:

1. The $\mathrm{O}_{3}$ atmospheric profile.

2. The continuum absorption of $\mathrm{N}_{2}, \mathrm{O}_{2}$ and $\mathrm{H}_{2} \mathrm{O}$ using the model MPM93 (Liebe et al., 1993). Those models are used to calculate the opacity of the atmosphere due to those three species. The opacity is also used to calculate the emission of the troposphere. The fitted variables are the absorption coefficients at different altitudes.

3. Spectral artifacts (i.e. standing waves) on the measured spectrum. Such are created by mismatches and nonideal reflectors in the quasi optical system which cannot be totally avoided. If a reflector can be identified to cause a certain standing wave component, the associated wavelength is explicitly included in the retrieval. For the remaining components, the wavelengths are determined empirically from the spectra.

The set of parameters (a priori profile, covariance matrices, standing wave wavelengths) used for the retrievals is kept constant for the whole dataset.

\subsubsection{Performance of the retrieval}

Retrieval assessment is done via the averaging kernel (AVK) matrix, $\mathbf{A}$, which is defined as

$\mathbf{A}=\frac{\partial \hat{\boldsymbol{x}}}{\partial \boldsymbol{x}}=\mathbf{D} \mathbf{K}$

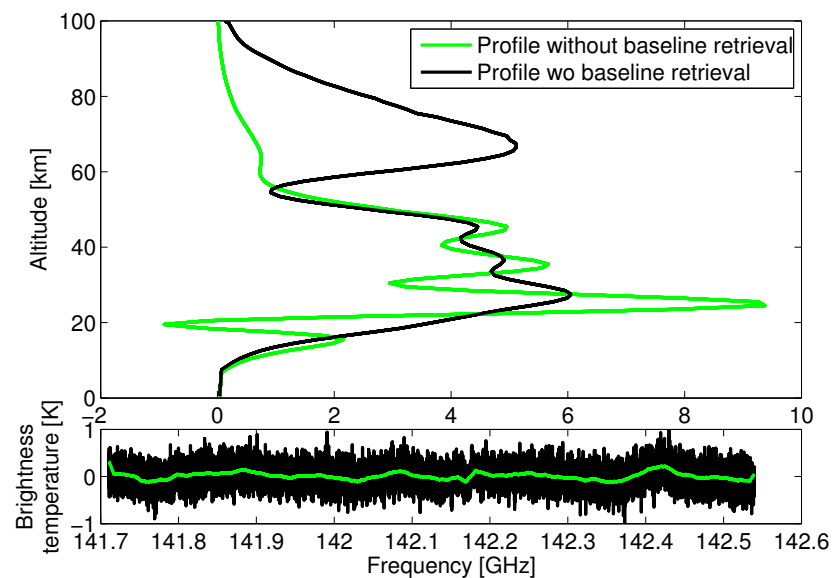

Fig. 6. A retrieval of the spectrum 25 February 2009 (same spectrum as in Figs. 3 and 4) without the retrieval of the sinusoidal baseline features. A running mean has been applied to the residuum (green line).

where $\hat{x}$ denotes the retrieved quantity and $\boldsymbol{x}$ the true quantity of interest. Following Rodgers (2000) the averaging kernel matrix, A, can be used to rearrange Eq. (7) to yield an instrument function

$\hat{\boldsymbol{x}}=\boldsymbol{x}_{\mathrm{A}}+\mathbf{A}\left(\boldsymbol{x}-\boldsymbol{x}_{\mathrm{A}}\right)$,

which describes how the instrument/retrieval "sees" the original quantity of interest.

Two sets of OZORAM AVKs are plotted in Fig. 5, both corresponding to measurements integrated one hour.

\section{Retrieval of baseline features}

Baseline features of the spectrum are part of the retrieved state. That means, that they do not create a random or systematic error on the retrieved $\mathrm{O}_{3}$-profile, but influence the $\mathrm{O}_{3}$-profile via the regularization. This can be observed in the breakoff of the AVK (see Fig. 5) for 2008 onwards.

In order to show the influences of the retrieval of those auxiliary parameters the night spectrum of 25 February (see Fig. 3) has been retrieved without the fitting of the baseline parameters (see Fig. 6). While the retrieval still converges, i.e. some VMR profile is returned, this profile does not look sensible and artifacts are clearly visible in the residuum.

Two features in the retrieved profile without the retrieval of waves are striking. The strong negative VMR at $20 \mathrm{~km}$. This can be ruled out for physical reasons. The night enhancement of $\mathrm{O}_{3}$ in the mesosphere vanishes almost completely. Comparison with independent data (in Sect. 3) does however show, that this enhancement is also present in other measurements.

Because the baseline features or parts thereof may be used to construct the emission line (baseline and atmospheric spectrum are not necessarily linearly independent), it cannot be said from the measurement alone where the sinusoidal 
features come originally from, i.e. error in the forward modeling or true baseline features of the instrument. In order to evaluate the effectiveness of the baseline retrieval independent information is used (e.g. independent measurements, physical reasoning).

\subsection{Error discussion}

Following Rodgers (2000), the error in the retrieved profile $\hat{\boldsymbol{x}}$ can be written as

$$
\begin{aligned}
\hat{\boldsymbol{x}}-\boldsymbol{x} & =(\mathbf{A}-\mathbf{I})\left(\boldsymbol{x}-\boldsymbol{x}_{\mathbf{A}}\right) \\
& +\mathbf{D} \mathbf{K}_{\mathbf{b}}(\boldsymbol{b}-\hat{\boldsymbol{b}}) \\
& +\mathbf{D} \Delta F(\boldsymbol{x}, \boldsymbol{b}, \hat{\boldsymbol{b}}) \\
& +\mathbf{D} \epsilon .
\end{aligned}
$$

The vector $\hat{\boldsymbol{b}}$ holds estimates of the parameters, $\boldsymbol{b} . \mathbf{K}_{b}$ denotes the Jacobian of the forward model with respect to the parameters $\boldsymbol{b} . \Delta F$ is the difference of the forward model implementation to the (unknown) true or perfect forward model.

\subsubsection{Smoothing error}

The smoothing error, Eq. (10), is caused by the low altitude resolution of the data retrieved from the measurement which is equivalent to applying a running weighted average, encoded in the averaging kernels, to the true profile $\boldsymbol{x}$. In order to calculate this error, however, detailed knowledge about the statistics of a true ensemble of the $\mathrm{O}_{3}$ profile is necessary (Rodgers, 2000, p. 49).

For this data set, it has been decided not attempt to quantify this error. Instead, the a priori profiles, $\boldsymbol{x}_{\mathrm{A}}$, and the averaging kernel matrices, $\mathbf{A}$, are explicitly included with the retrieved profiles, $\hat{\boldsymbol{x}}$, as essential part of the data sets.

\subsubsection{Forward model parameters}

The error caused by uncertainties in the forward model parameters, Eq. (11), is estimated using the instrument function, Eq. (9). The AVK matrix with respect to the parameters, $\boldsymbol{b}$, is calculated via:

$\mathbf{A}_{b}=\frac{\partial \hat{\boldsymbol{x}}}{\partial \boldsymbol{b}}=\mathbf{D} \mathbf{K}_{b}$.

Using an estimated covariance matrix for the parameters, $\mathbf{S}_{b}$, the covariance matrix, $\mathbf{S}_{\mathrm{fp}}$, of the retrieved profile is calculated by

$\mathbf{S}_{\mathrm{fp}}=\mathbf{A}_{b} \mathbf{S}_{b} \mathbf{A}_{b}^{T}$

The standard deviation $\sigma_{\mathrm{fp}}$ of the profile caused by the error in the forward model parameter is

$\sigma_{\mathrm{fp}}^{i}=\sqrt{\mathbf{S}_{\mathrm{fp}}^{i i}}$,

neglecting off-diagonal entries.

\subsubsection{Forward model error}

The error caused by a wrong forward model, Eq. (12), can only be estimated by comparison with independent data. The forward model ARTS which is used here has been investigated and compared to other forward models by Melsheimer et al. (2005).

\subsubsection{Noise error}

The noise error $\sigma_{\eta}$ is calculated from the measurement noise, $\mathbf{S}_{\epsilon}$ using Eq. (13). It is usually the error contribution which is easiest to calculate:

$\mathbf{S}_{\eta}=\mathbf{D} \mathbf{S}_{\epsilon} \mathbf{D}^{T}$

$\sigma_{\eta}^{i}=\sqrt{\mathbf{S}_{\eta}^{i i}}$

\subsubsection{Summary of error discussion}

Figure 7 presents a selection of the errors described above. This study is restricted to the errors which are caused by wrong spectroscopic parameters, a wrong temperature profile, wrong temperature of the cold calibration load, and measurement noise. The error due to wrong theoretical assumptions on the spectroscopy itself is difficult to estimate without proper spectroscopic measurements. The error figures used for the calculation are summarized in Table 3. The spectroscopic error consists of three parameters, the errors of line intensity, $I_{0}$, pressure broadening parameter, $\gamma_{\text {AIR }}\left(T_{0}\right)$, and temperature dependence of the pressure broadening parameter, $n_{\mathrm{AIR}}$. The noise error $\sigma_{\eta}$ has been calculated for the typical noise figure of a $1 \mathrm{~h}$ measurement.

From Fig. 7 the following conclusions can be drawn:

1. The error due to a wrong temperature of the cold calibration load, $\sigma_{\mathrm{Tc}}$, is negligible.

2. The error pattern due to spectroscopic uncertainties, $\sigma_{\mathrm{fp}}$, leads to an oscillation in the uncertainty of the retrieved profile.

3. The spectroscopic error dominates the error due to measurement noise up to the stratopause. Above the stratopause the measurement error becomes more influential due to the low signal.

\subsection{A cautionary note}

The retrieved profile may deviate from the true profile considerably, especially at the altitude limits. For example the night time profile in Fig. 4 shows a significant enhancement compared to the a priori at $70 \mathrm{~km}$, suggesting that such a feature exists in the real atmospheric state. However, the AVK (see Fig. 5) indicate that OZORAM would not be able to resolve such a feature. 
Table 3. Individual error figures contributing to the error budget for $\mathrm{O}_{3}$ retrievals from the $142.176 \mathrm{GHz}$ line as plotted in Fig. 7.

\begin{tabular}{llclr}
\hline Quantity & Symbol used & $\begin{array}{c}\text { Error reported } \\
\text { in reference }\end{array}$ & Reference & Error assumed \\
\hline $\begin{array}{l}\text { Line intensity } \\
\text { Pressure broadening }\end{array}$ & $I_{0}$ & $1 \%$ & HITRAN & $1 \%$ \\
$\begin{array}{l}\text { Temperature dependency } \\
\text { of } \gamma_{\text {AIR }}\left(T_{0}\right)\end{array}$ & $n_{\text {AIR }}\left(T_{0}\right)$ & $5 \% \leq \sigma_{\gamma_{\text {AIR }}\left(T_{0}\right)<10 \%}$ & HITRAN & $5 \%$ \\
$\begin{array}{l}\text { Temperature profile } \\
\text { Temperature of cold }\end{array}$ & $T$ & $\begin{array}{c}10 \% \leq \sigma_{n_{\text {AIR }}}<20 \% \\
\text { none }\end{array}$ & $\begin{array}{l}\text { HITRAN } \\
\text { none }\end{array}$ & $10 \%$ \\
calibration load & $T_{\mathrm{c}}$ & $1 \%$ & Manual of sensor & $5 \%$ \\
\hline
\end{tabular}

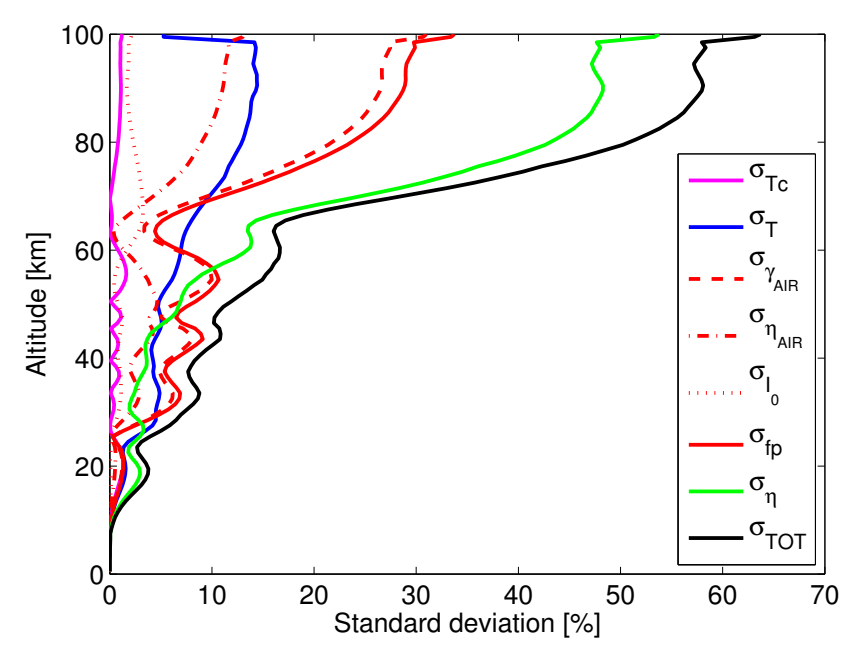

Fig. 7. Uncertainty in the profile due to errors in the instrumental parameters and spectroscopy. The plot covers random error due to noise on the spectra, $\sigma_{\eta}$, and systematic error due to deviations in the temperature of the cold calibration load, $\sigma_{T_{\mathrm{C}}}$, in the atmospheric temperature profile, $\sigma_{T}$, and in spectroscopic parameters, namely pressure broadening, its temperature coefficient, and the line intensity, $\sigma_{\gamma_{\mathrm{AIR}}}, \sigma_{n_{\mathrm{AIR}}}$ and $\sigma_{T_{0}}$, respectively. $\sigma_{\mathrm{fp}}=\sqrt{\sigma_{\gamma_{\mathrm{AIR}}}^{2}+\sigma_{n_{\mathrm{AIR}}}^{2}+\sigma_{I_{0}}^{2}}$ and $\sigma_{\mathrm{TOT}}=\sqrt{\sigma_{T_{\mathrm{C}}}^{2}+\sigma_{T}^{2}+\sigma_{\mathrm{fp}}^{2}+\sigma_{\eta}^{2}}$.

The retrieval above $70 \mathrm{~km}$ altitude (for the configuration from 2008) is a mixture of profile and columnar information as determined by the instrument function, Eq. (9).

Therefore, the AVK matrix and the a priori are essential parts of the data set. Profiles cannot be interpreted correctly without taking into account the instrument function, Eq. (9).

\section{Intercomparison of the OZORAM data set with independent data sets}

\subsection{General}

The OZORAM profiles are compared to two independent data sets. The spectra measured by OZORAM have been analysed using two different spectroscopic data sets (see Table 2 for details):

- the HITRAN database as of 2004 (Rothman et al., 2005), and

- line intensities from the JPL catalogoue as of 2009 (Pickett et al., 2010), appended with empirically determined line shape parameters found in the spectroscopic database of the ARTS package.

The comparison itself is carried out in terms of "simulated retrieval" (Rodgers and Connor, 2003): Let $\hat{\boldsymbol{x}}_{\mathrm{OR}}$ denote the profiles retrieved from OZORAM measurements and $\hat{\boldsymbol{x}}_{\mathrm{IM}}$ be profiles from an independent source. The simulated retrieval, $\hat{\boldsymbol{x}}_{\mathrm{SIM}}$, is the profile the OZORAM would "see" if the independent measurement would represent the true atmosphere,

$\hat{\boldsymbol{x}}_{\mathrm{SIM}}=\boldsymbol{x}_{\mathrm{OR}}^{\mathrm{A}}+\mathbf{A}_{\mathrm{OR}}\left(x_{\mathrm{IM}}-\boldsymbol{x}_{\mathrm{OR}}^{\mathrm{A}}\right)$.

Comparing OZORAM retrievals to simulated retrievals of the independent source yields a difference profile

$\hat{\boldsymbol{\delta}}_{x}=\hat{\boldsymbol{x}}_{\mathrm{SIM}}-\hat{\boldsymbol{x}}_{\mathrm{OR}}$,

and covariance matrix

$$
\begin{aligned}
\mathbf{S}_{\delta_{x}} & =\mathbf{A}_{\mathrm{OR}}\left(1-\mathbf{A}_{\mathrm{IM}}\right) \mathbf{S}_{\mathrm{OR}}\left(1-\mathbf{A}_{\mathrm{IM}}\right)^{T} \mathbf{A}_{\mathrm{OR}}^{T} \\
& +\mathbf{S}_{\mathrm{OR}}+\mathbf{A}_{\mathrm{OR}} \mathbf{S}_{\mathrm{IM}} \mathbf{A}_{\mathrm{OR}}^{T},
\end{aligned}
$$

where $\mathbf{A}_{\mathrm{IM}}$ are the averaging kernels for the independent data sets and the $\mathbf{S}_{\mathrm{IM}}$ are the error covariance matrices of the independent data.

Two satellite instruments have been chosen for the comparison, MLS onboard the EOS Aura satellite and SABER 
Table 4. Number of collocations for OZORAM comparison with the satellite instruments MLS and SABER. Both datasets, OZORAM-HITRAN and OZORAM-JPL, yield the same number of collocations.

\begin{tabular}{ccccccc}
\hline & \multicolumn{2}{c}{ MLS } & & \multicolumn{2}{c}{ SABER } \\
\cline { 2 - 3 } \cline { 5 - 6 } & night & day & & night & day \\
\hline OZORAM & 155 & 204 & & 124 & 18 \\
\hline
\end{tabular}

onboard the TIMED satellite. While the EOS MLS O 3 primarily covers the stratosphere, SABER is investigating the mesosphere and above.

The satellite measurements were considered for comparison if their ground pixel center was no more than $500 \mathrm{~km}$ away from the intersection of the OZORAM line of sight with the $60 \mathrm{~km}$ altitude layer, and if there was an OZORAM measurement within $1 \mathrm{~h}$ of the satellite measurement. Stronger limitations on coincidence distance and time did not alter the results significantly but reduced the number of matches. This is in agreement with the findings of Hocke et al. (2007) who studied the dependence of the comparison on different matching criteria in space and time. Table 4 lists the number of OZORAM collocations with either satellite instrument, separated for day and night.

Because of the strong diurnal cycle in upper stratospheric and mesospheric $\mathrm{O}_{3}$, the comparison has been divided into night and day time measurements. At $60 \mathrm{~km}$ altitude the daynight terminator is given by a solar zenith angle (SZA) of about $95^{\circ}$. Hence a satellite measurement is defined to be a daytime measurement if the SZA of the ground pixel center is less than $90^{\circ}$, and a night measurement is defined by a SZA larger than $100^{\circ}$.

The measurements of both instruments have been interpolated to the OZORAM altitude grid $(0.5 \ldots 100.5 \mathrm{~km}$ in $1 \mathrm{~km}$ intervals). Outside the sensitive altitude ranges of the satellite instruments, profile information was replaced with the OZORAM a priori. The interpolated data have been degraded to the OZORAM altitude resolution using simulated retrieval, Eq. (19).

\subsection{The satellite instruments}

\subsubsection{EOS MLS onboard Aura}

EOS MLS (Earth Observing System Microwave Limb Sounder) is a millimeterwave radiometer onboard the Aura satellite (Waters et al., 2006) operating in limb geometry. Among others it observes the $\mathrm{O}_{3}$ rotational emission at $240 \mathrm{GHz}$. Because Aura is a polar orbiting satellite there are frequent measurements above $\mathrm{Ny}$-Ålesund. The $\mathrm{O}_{3}$ profiles, version v2.2, derived from MLS measurements (Waters et al., 2006), are denoted by $\boldsymbol{x}_{\text {MLS }}$.
Table 5. Errors defined for the SABER data set. The error figures follow Huang et al. (2008).

\begin{tabular}{lrrrr}
\hline Altitude [km] & 10 & 50 & 60 & 100 \\
Error [\%] & 10 & 10 & 20 & 40 \\
\hline
\end{tabular}

The error on the retrieved profile is part of the EOS MLS dataset that has been used in this publication. The MLS AVK matrix, involved in the calculation of $\mathbf{S}_{\delta_{x}}$ in Eq. (21), is modelled using the data description that is part of the MLS data set.

\subsubsection{SABER onboard TIMED}

The SABER instrument onboard the TIMED satellite is dedicated to mesospheric and lower thermospheric research. The data used in this publication comprise $\mathrm{O}_{3}$ profiles (version 1.07), $\boldsymbol{x}_{\mathrm{SABER}}$, derived from emissions at $9.6 \mu \mathrm{m}$. SABER is also operating in limb scanning mode. SABER profile errors are interpolated from the values given in Table 5. The AVK matrix is assumed to be unity for the SABER data interpolated to OZORAM altitude resolution.

\subsection{Results of the intercomparison}

Figure 8 displays the time series of collocations of the OZORAM-JPL dataset with MLS (lower rows) and SABER data (upper rows). Generally the correlation of the time series is very good when taking into account the altitude ranges of the instruments. This is also reflected in the correlation coefficients plotted in Fig. 9.

There is significant correlation over the whole altitude range between the SABER and OZORAM-JPL night time results. The MLS night time data are significantly correlated to OZORAM-JPL up to $70 \mathrm{~km}$ altitude, although the absolute levels differ considerably.

The comparison of day time measurements shows also a significant correlation between MLS and the two OZORAM data sets up to $55 \mathrm{~km}$. The lower maximum altitude may be explained by the much weaker signal, which renders the noise on the data more influencial. The SABER day time results hardly correlate to the OZORAM data sets, except around at $60 \mathrm{~km}$ altitude. However, the number of collocations (see Table 4 for details) is too small for a definitive statement about this part of the comparison.

The mean of the difference profiles $\boldsymbol{\delta}_{x}$ (blue solid lines) and standard deviation $\boldsymbol{s}_{\delta_{x}}$ (black solid lines; see Eq. 18) are shown in Fig. 10 for OZORAM-HIT (left column), and OZORAM-JPL (right column). Because the deviation from zero in the difference profiles $\delta_{X}$ is not correlated to the VMR values in the profiles up to the stratopause, the differences in VMR are plotted. Above the stratopause the VMR levels of 


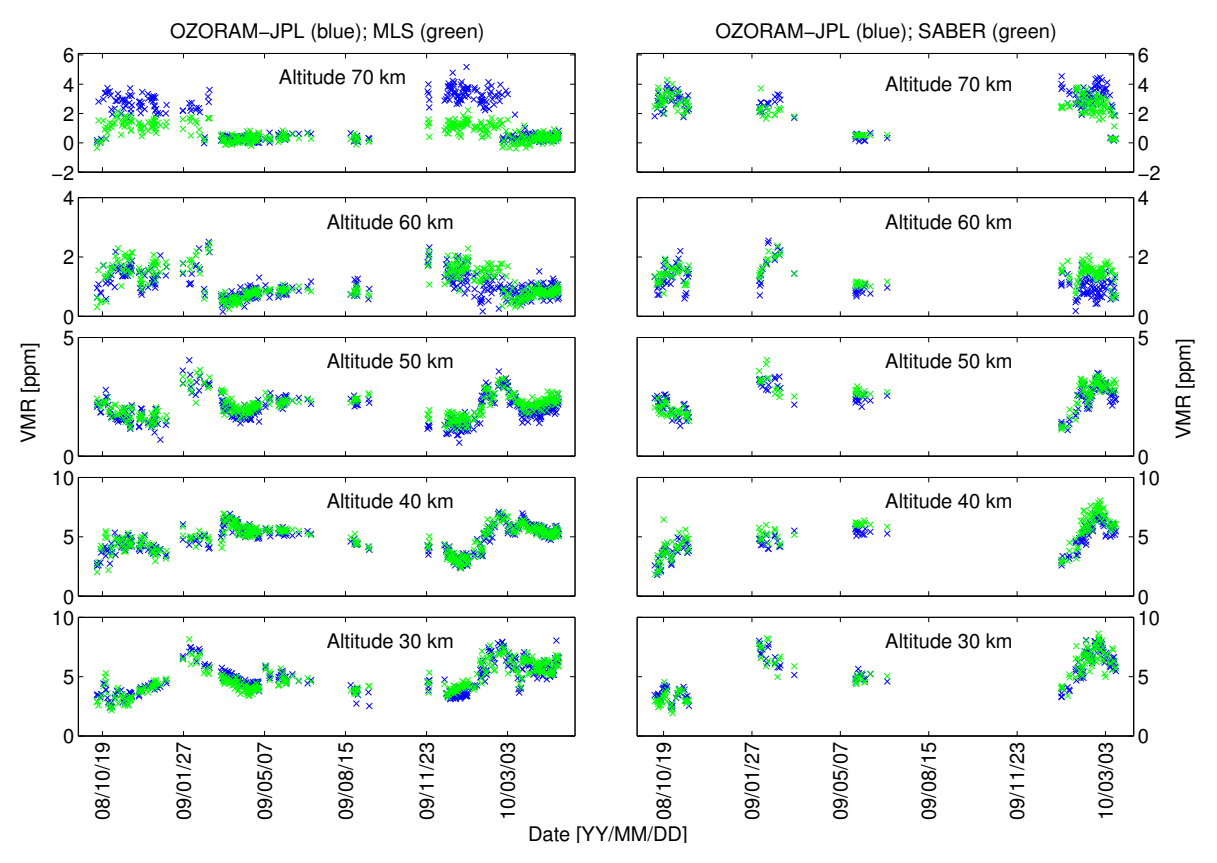

Fig. 8. Time series of the OZORAM-JPL data set versus MLS data (left panels) and SABER data (right panel). Plotted are matching pairs, the satellite data have been smoothed according to Eq. (9). See Fig. 9 for details on the correlation of the values retrieved in each altitude. The comparison shows (in conjunction with Fig. 5b), that measurements up to $70 \mathrm{~km}$ altitude can be used to observe changes in the $\mathrm{O}_{3} \mathrm{VMR}$.

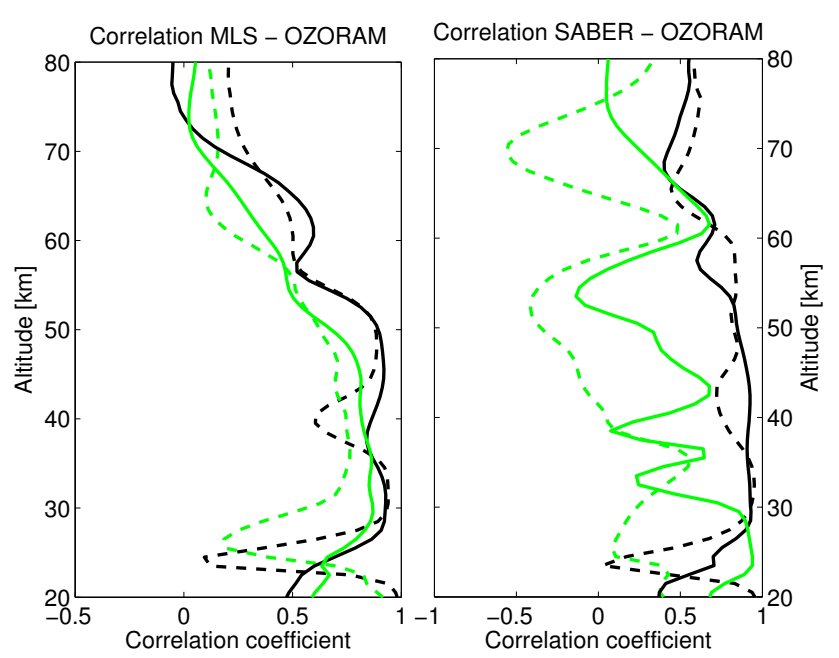

Fig. 9. Correlation of the OZORAM-JPL (solid lines) and the OZORAM-HIT (dashed lines) datasets to the satellite instruments MLS (left panel) and SABER (right panel). The correlation has been calculated separately for the day time (green lines) and the night time measurements (black lines).

$\mathrm{O}_{3}$ are influenced by the results (and the errors therein) in lower altitudes (see Sect. 2.4.3 for further details).

For orientation, the contours for three percentages, $10 \%$, $20 \%$, and $30 \%$, have been plotted using green dashed lines. They have been calculated using the mean profiles over all profiles which are compared with the particular satellite dataset. The black dashed lines display the standard deviation $\boldsymbol{\sigma}_{\delta_{x}}=\sqrt{S_{\delta_{x}}^{i i}}$ of the difference profiles $\boldsymbol{\delta}_{x}$.

Within the error bars, the measurements largely agree. The disagreement is comparable to the disagreement shown by Boyd et al. (2007) if one takes into account the higher $\mathrm{O}_{3}$ levels at subtropical latitudes. Nevertheless the disagreements are larger than those shown by Hocke et al. (2007) for the SOMORA millimeter wave radiometer, both in relative and absolute units.

The comparison in Fig. 10 shows a distinct oscillatory deviation. Because the pattern of this oscillation is similar in all comparisons, it is most likely a characteristic of the OZORAM data sets. The oscillatory deviation is constant for the time of the comparison. A similar structure has been reported for ground-based microwave data by Boyd et al. (2007) who record the $\left(6_{1,5} \rightarrow 6_{0,6}\right)$ emission of $\mathrm{O}_{3}$ at $110.836 \mathrm{GHz}$ and also compare to MLS data. Boyd et al. (2007) also attribute the oscillatory structure to the ground-based measurements because the same structure is seen for comparisons with different instruments. Hocke et al. (2007) record the same $\mathrm{O}_{3}$ transition but use different spectroscopic parameters. They also find an oscillatory structure in comparison to MLS $\mathrm{O}_{3}$, but considerably smaller than the one presented here. A more detailed analysis would require detailed knowledge of the instruments and the retrieval software and parameters used by Boyd et al. (2007) and Hocke et al. (2007). Simply adopting the spectroscopic parameters from the SOMORA set-up (Calisesi, 2000) for OZORAM did not improve the comparison considerably. 


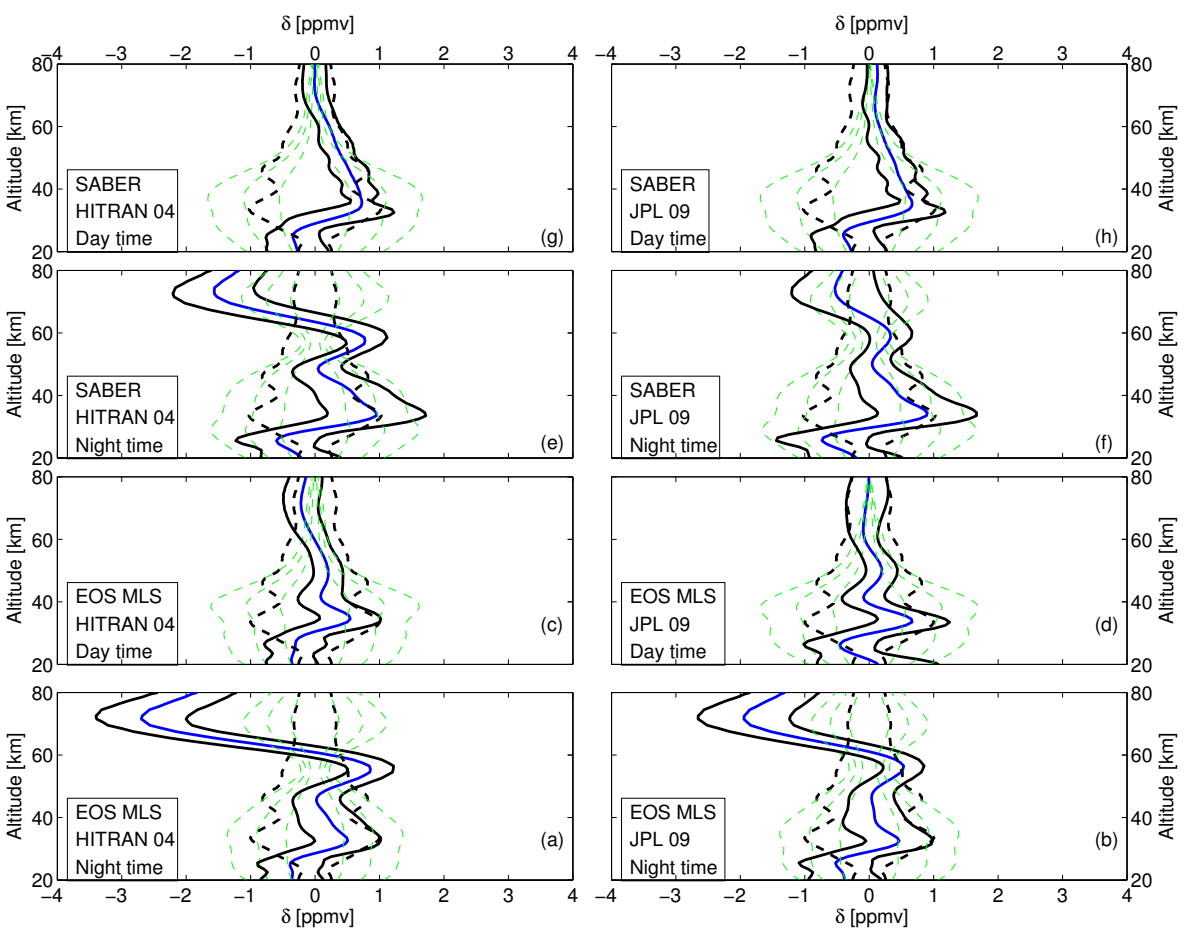

Fig. 10. Intercomparison of the OZORAM data set, using HITRAN 2004 (left column) and JPL 2009 spectroscopy (right column), respectively, to the measurements of EOS MLS (IM = MLS; lower two rows) and SABER (IM=SABER; upper two rows). The plots show the mean difference $\left\langle\delta_{x}\right\rangle=\left\langle\hat{\boldsymbol{x}}_{\mathrm{IM}}-\hat{\boldsymbol{x}}_{\mathrm{OR}}\right\rangle$ and the standard deviation of the differences of the difference profiles $\delta_{x}$ (solid black). (solid blue; See Sect. 3.1 for further details). The standard deviation of the $\left\langle\delta_{x}\right\rangle, s_{\delta_{x}}^{i i}=\sqrt{S_{\delta_{x}}^{i i}}$, is denoted by black solid lines, the black dashed lines denote the error of the difference $\sqrt{S_{\delta_{y}}^{i i}}$. The green dashed lines mark the $10 \%, 20 \%$ and $30 \%$ (starting from the innermost line) ranges of the mean OZORAM profile $\left(1 / N \sum_{n=1}^{N} \hat{\boldsymbol{x}}_{\mathrm{OR}}^{n}\right)$.

The comparison with SABER profiles, $\boldsymbol{x}_{\mathrm{SABER}}$, yields similar results as the comparison to EOS MLS profiles. The general shape of the oscillatory deviation on the retrieved profiles is the same for both instruments. There is a notable difference between the night time profile comparisons for OZORAM-HIT and OZORAM-JPL in the mesosphere, Fig. 10e and f, respectively. While the night time comparison of the OZORAM-HIT and the SABER data shows a deviation almost as large as the comparison to the EOS MLS data, the deviation drops below $0.5 \mathrm{ppm}$ or $20 \%$ when the OZORAM-JPL dataset is used.

\section{Conclusions}

This work introduces the ground-based millimeter wave radiometer OZORAM monitoring the $142 \mathrm{GHzO}_{3}$ emission line from the AWIPEV research base on the Spitsbergen archipelago in the high Arctic $\left(79^{\circ} \mathrm{N}\right)$. It describes the modifications that enable the instrument to measure stratomesospheric $\mathrm{O}_{3}$ profiles with a time resolution of about $1 \mathrm{~h}$ and a moderate altitude resolution of about 10-20 km (FWHM). The radiative transfer and the retrieval setup are summarized and the error budget is discussed. OZORAM spectra have been analysed using two different spectroscopic data sets, HITRAN 2004 and a combined catalogue using the JPL 2009 catalogue appended with empirically determined line shape parameters from the ARTS package.

Comparisons with the MLS and the SABER instruments show general agreement with at most $20 \%$ deviation in the stratosphere and up to $30 \%$ deviation in the mesosphere. The comparison yields a distinct systematic oscillatory structure on the OZORAM measurements. This applies for the use of both spectroscopic catalogs, HITRAN 2004 and JPL/ARTS, although JPL/ARTS catalog produces results closer to satellite measurements in this study.

Compared to similar studies of $\mathrm{O}_{3}$ millimeter wave radiometer performance it can be said that OZORAM performs within the precision already known for millimeter wave radiometers while the accuracy is not as good as presented in other works.

Because the oscillatory deviation is systematic and constant over the studied period of time, the measurements are nonetheless well suited to the study of variations on shorter and larger time scales. 
Acknowledgements. This study was supported by the DFG priority program CAWSES in the projects SACOSAT I, SACOSAT II and SACOSAT III.

The EOS MLS data used in this study were acquired as part of the activities of NASA's Science Mission Directorate, and are archived and distributed by the Goddard Earth Sciences (GES) Data and Information Services Center (DISC).

The TIMED-SABER data were retrieved from ftp://saber.gats-inc. com/. We thank the science and data processing team of TIMEDSABER.

ECMWF Operational Analysis data used in this study have been obtained from the ECMWF Data Server.

The staff on the AWIPEV research base was very helpful in keeping the instrument running and performing several minor repairs.

Edited by: P. K. Bhartia

\section{References}

Benz, A. O., Grigis, P. C., Hungerbühler, V., Meyer, H., Monstein, C., Stuber, B., and Zardet, D.: A broadband FFT spectrometer for radio and millimeter astronomy, Astron. Astrophys., 442, 767773, doi:10.1051/0004-6361:20053568, 2005.

Boyd, I. S., Parrish, A. D., Froidevaux, L., von Clarmann, T., Kyrölä, E., Russell III, J. M. R., and Zawodny, J. M.: Groundbased microwave ozone radiometer measurements compared with Aura-MLS v2.2 and other instruments at two Network for Detection of Atmospheric Composition Change sites, J. Geophys. Res., 112, D24S33, doi:10.1029/2007JD008720, 2007.

Bühler, S., Eriksson, P., Kuhn, T., von Engeln, A., and Verdes, C.: ARTS, the atmospheric radiative transfer simulator, J. Quant. Spectrosc. Ra., 91, 65-93, doi:10.1016/j.jqsrt.2004.05. 051, 2005.

Calisesi, Y.: Monitoring of Stratospheric and Mesospheric Ozone with a Ground-based Microwave radiometer: Data retrieval, Analysis, and Applications, Ph.D. thesis, Universit"at Bern, 2000.

Connor, B. J., Siskind, D. E., Tsou, J. J., Parrish, A., and Remsberg, E. E.: Ground-based microwave observation of ozone in the upper stratosphere and mesosphere, J. Geophys. Res., 99, 1675716770, 1994.

Farman, J. C., Gardiner, B. G., and Shanklin, J. D.: Large losses of total ozone in Antarctica reveal seasonal $\mathrm{ClO}_{\mathrm{x}} / \mathrm{NO}_{\mathrm{x}}$ interaction, Nature, 315, 207-210, doi:10.1038/315207a0, 1985.

Hocke, K., Kämpfer, N., Ruffieux, D., Froidevaux, L., Parrish, A., Boyd, I., von Clarmann, T., Steck, T., Timofeyev, Y. M., Polyakov, A. V., and Kyrölä, E.: Comparison and synergy of stratospheric ozone measurements by satellite limb sounders and the ground-based microwave radiometer SOMORA, Atmos. Chem. Phys., 7, 4117-4131, doi:10.5194/acp-7-4117-2007, 2007.

Huang, F. T., Mayr, H. G., Russell III, J. M. R., Mlynczak, M. G., and Reber, C. A.: Ozone diurnal variations and mean profiles in the mesosphere, lower thermosphere, and stratosphere, based on measurements from SABER on TIMED, J. Geophys. Res., 113, A04307, doi:10.1029/2007JA012739, 2008.

Janssen, M. A.: Atmospheric Remote Sensing by Microwave Radiometry, John Wiley \& Sons, Inc., New York, 1993.
Klein, U.: Aufbau und Betrieb eines breitbandigen, bodengestützen Millimeterwellen-Radiometers zur Messung atmosphärischer Spurenstoffe, Ph.D. thesis, Universität Bremen, 1993.

Klein, U., Barry, B., Lindner, K., Wohltmann, I., and Künzi, K. F.: Winter and Spring Observations of Stratospheric Chlorine Monoxide from Ny-Ålesund, Spitsbergen, in 1997/98 and 1998/99, Geophys. Res. Lett., 27, 4093-4097, 2000.

Klein, U., Wohltmann, I., Lindner, K., and Künzi, K. F.: Ozone depletion and chlorine activation in the Arctic winter 1999/2000 observed in Ny-Ålesund, J. Geophys. Res., 107, 8288, doi:10. 1029/2001JD000543, 2002.

Lary, D. J.: Catalytic destruction of stratospheric ozone, J. Geophys. Res., 102, 21515-21526, 1997.

Liebe, H. J., Hufford, G. A., and Cotton, M. G.: Propagation modeling of moist air and suspended water/ice particles at frequencies below $1000 \mathrm{GHz}$, in: Proc. AGARD 52nd Spec. Meeting EM Wave Propag. Panel, Palma De Maiorca, Spain, 3.1-3.10., 1993.

Melsheimer, C., Verdes, C., Buehler, S., Emde, C., Eriksson, P., Feist, D., Ichizawa, S., John, V., Kasai, Y., Kopp, G., Koulev, N., Kuhn, T., Lemke, O., Ochiai, S., Schreier, F., Sreerekha, T., Suzuki, M., Takahashi, C., Tsujimaru, S., and Urban, J.: Intercomparison of general purpose clear sky atmospheric radiative transfer models for the millimeter/submillimeter spectral range, Radio Sci., 40, RS1007, doi:10.1029/2004RS003110, 2005.

Penfield, H., Litvak, M., Gottlieb, C., and Lillley, A.: Mesospheric ozone measured from ground-based millimeter wave observations, J. Geophys. Res.-Space, 81, 6115-6120, 1976.

Pickett, H. M., Poynter, R. L., Cohen, E. A., Delitsky, M. L., Pearson, J. C., and Mueller, H. S. P.: Submillimeter, millimeter, and microwave spectral line catalog (Reprint from J. Quant Spectrosc. Ra., 60, 883-890, 1998), J. Quant. Spectrosc. Ra., 111, 1617-1624, 2010.

Randall, C. E., Harvey, V. L., Manney, G. L., Orsolini, Y., Codrescu, M., Sioris, C., Brohede, S., Haley, C. S., Gordley, L. L., Zawodny, J. M., and Russell III, J. M.: Stratospheric effects of energetic particle precipitation in 2003-2004, Geophys. Res. Lett., 32, L05802, doi:10.1029/2004GL022003, 2005.

Rodgers, C. D.: Inverse Methods for Atmospheric Sounding, World Scientific Publishing Co. Pte. Ltd., Singapore, 2000.

Rodgers, C. D. and Connor, B. J.: Intercomparison of remote sounding instruments, J. Geophys. Res., 108, 4116, doi:10.1029/ 2002JD002299, 2003.

Rothman, L. S., Jacquemart, D., Barbe, A., Benner, D. C., Birk, M., Brown, L. R., Carleer, M. R., Chackerian, C., Chance, K., Coudert, L. H., Dana, V., Devi, V. M., Flaud, J. M., Gamache, R. R., Goldman, A., Hartmann, J. M., Jucks, K. W., Maki, A. G., Mandin, J. Y., Massie, S. T., Orphal, J., Perrin, A., Rinsland, C. P., Smith, M. A. H., Tennyson, J., Tolchenov, R. N., Toth, R. A., Vander Auwera, J., Varanasi, P., and Wagner, G.: The HITRAN 2004 molecular spectroscopic database, J. Quant. Spectrosc. Ra., 96, 139-204, 2005.

Russell III, J., Mlynczak, M., and Gordley, L.: An Overview of the SABER Experiment for the TIMED Mission, in: Optical Spectroscopic Techniques and Instrumentation for Atmospheric and Space Research, edited by: Wang, J. and Hays, P. B., vol. 2266 of Proceedings of the Society of Photo-Optical Instrumentation Engineers (SPIE), SOC Photo Opt Instrumentation Engineers, SPIE - Int Soc Optical Engineering, Bellingham, Optical Spectroscopic Techniques and 
Instrumentation for Atmospheric and Space Research Conference, San Diego, CA, 25-27 July 1994, 406-415, 1994.

Schoeberl, M. R., Douglass, A. R., Hilsenrath, E., Bhartia, P. K., Beer, R., Waters, J. W., Gunson, M. R., Froidevaux, L., Gille, J. C., Barnett, J. J., Levelt, P. E., and DeCola, P.: Overview of the EOS Aura Mission, IEEE T. Geosci. Remote, 44, 1066-1074, doi:10.1109/TGRS.2005.861950, 2006

Sinnhuber, B.-M., Langer, J., Klein, U., Raffalski, U., Künzi, K., and Schrems, O.: Ground based millimeter-wave observations of Arctic ozone depletion during winter and spring of 1996/97, Geophys. Res. Lett., 25, 3227-3330, doi:10.1029/98GL52488, 1998.

Tsou, J. J., Connor, B. J., Parrish, A., McDermid, I. S., and Chu, W. P.: Ground-based microwave monitoring of middle atmosphere ozone: Comparison to lidar and Stratospheric and Gas Experiment II satellite observations, J. Geophys. Res., 100, 3005 3016, 1995 .
Waters, J., Wilson, W., and Shimabakura, F.: Microwave measurement of mesospheric carbon-monoxide, Science, 191, 11741175, 1976.

Waters, J., Froidevaux, L., Harwood, R., Jarnot, R., Pickett, H., Read, W., Siegel, P., Cofield, R., Filipiak, M., Flower, D., Holden, J., Lau, G., Livesey, N., Manney, G., Pumphrey, H., Santee, M., Wu, D., Cuddy, D., Lay, R., Loo, M., Perun, V., Schwartz, M., Stek, P., Thurstans, R., Boyles, M., Chandra, K., Chavez, M., Chen, G., Chudasama, B., Dodge, R., Fuller, R., Girard, M., Jiang, J., Jiang, Y., Knosp, B., LaBelle, R., Lam, J., Lee, K., Miller, D., Oswald, J., Patel, N., Pukala, D., Quintero, O., Scaff, D., Van Snyder, W., Tope, M., Wagner, P., and Walch, M.: The Earth Observing System Microwave Limb Sounder (EOS MLS) on the Aura satellite, IEEE T. Geosci. Remote, 44, 1075-1092, doi:\{10.1109/TGRS.2006.873771\}, 2006.

Waters, J. W.: Ground-based Measurement of Millimetrewavelength Emission by Upper Stratospheric $\mathrm{O}_{2}$, Nature, 242, 506-508, 1973. 